\title{
Tourist souvenirs based on computer aided design
}

\author{
Xia Zhi-Liang \\ Wenzhou Vocational \& Technical College, Wenzhou. 325035 \\ Xia441@sina.com
}

Keywords: WenZhou; Souvenirs.Design

\begin{abstract}
With tourism' rapid development, tourist souvenirs has become an indispensable part in tourism,and the important value in culture and business which can not underestimate,let's set an example on souvenirs design works with WenZhou's local characteristics, which with attractions for the characteristic in WenZhou' regional division,and refining some elements such as : city flower 、 citytree 、 citylogo villarindustry 、 agricultural and sideline products to analyze and research.
\end{abstract}

\section{Introduction}

Along with the improvement of living standards, tourism is not a luxury thing,Especially holiday tourism has become an indispensable part of our life, souvenir has become part of the tourism's process,In the developed countries tourism shopping has reached $74 \%$,tourist souvenirs income far higher the ticket prices. The tourism shopping world average is $40 \%$, the national average is $20 \%$, with the tourism boom,the price of tickets also began to rise,but the tourism souvenirs which stand the city's cultural card tend to be the same, and lack of regional cultural characteristics.

\section{Tourist souvenirs design characterized by WenZhou region shape}

1.1 Ouplate,what's the meaning of “ou"is small pots v plates and cups,also the other call of WenZhou in ZheJiang province in china. The fruits plate external members as Fig 1shows,it's design resource is "ou”, eight fruit plates apparently represent YongJia、LeQing、WenZhou、RuiAn、 WenCheng、PingYang、ShunTai、CangNan,the appearance is according to each region boundary formation,Wenzhou tourist map as the applique pattern,it not only can be used as a fruit tray,also can temporarily used as a map 。 The tourism souvenir plate,it's material is ceramic,environmental protection free from contamination,which is the best gift for Household or relatives and friends.

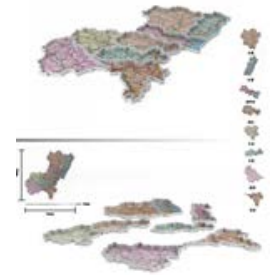

Fig1 Tourist souvenirs fruit plates

1.2 Manufacture kinds of educational form chess based on the idea of wenzhou region boundary which loved by children and old men.

The principle of WenZhou tourism chess similar to air chess,we used the WenZhou map which with represent and symbolic significance as the main body of the work,tourist chess with wenzhou characteristic extremely from the design pitch,stick to the wenzhoutheme,which can realize closely integration with WenZhou's tourism resource.The board game map is wenzhou topographic map,each station is wenzhou's famous attraction,such as in the 5A scenic spot mountain Yandang,Pieces have to stay here like a real journey,in addition there are corresponding scenic names and pictures in the tourism chess accessory's scenic cards'front,on the reverse side is the introduction of this scenic spot.So, in addition to entertainment, also can be used as wenzhou tourism brochure, greatly enhanced its extension. 
This entertaining tourist souvenirs, it pays attention to its practicability and publicity of wenzhou in the design, fully embody the characteristics of wenzhou.Through the game both promote the tourism characteristics of wenzhou, and popularize the knowledge related to the wenzhou including wenzhou local businesses, combined the design theme and wenzhou tourism resources closely,the tourists can forever memory the trip to wenzhou with a form of entertainment.In addition, the travel production cost is low, the craft is simple, the material is environmental, it's powerful to generalization, and suitable for both old and young, easy to realize the maximization of interests, very suitable for tourism products market.

Through this set of wenzhou tourism chess we can see the scenery, taste the humanities, play the souvenir's design concept. As Fig2 shows.

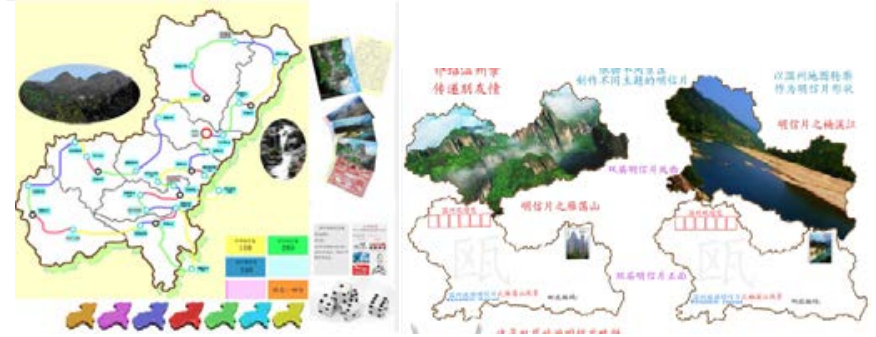

Fig2 The tourism chess on WenZhou theme Fig3 Tourism postcards with WenZhou theme 1.3 Tourist postcards

On appearance design, we use the most representative and symbolic wenzhou topographic map as the design basis,painted landscapes or local feature of wenzhou tourist postcards can use double deck design,on the opposite side of the postcard is wenzhoulandscape,give users a more intuitive feeling.On the double card's fold plane there are corresponding detail writing introduced,this allows people to have more in-depth understanding in wenzhou.

As a result of the communication function of the postcard,it's widely spread range and unique shape, will attract people's attention. Thus it has very good publicity effect in wenzhou and its tourism resources and folk customs.tourist postcards with wenzhou characteristic extremely from the design pitch,stick to the wenzhoutheme,which can realize closely integration with WenZhou's tourism resource. Except communication it also has collection function,many tourists visit WenZhou's scenic spot in order to collect a full set of wenzhou tourism postcards.

Through this set of wenzhou tourism postcards we can see the scenery, taste the humanities, play the souvenir's design concept. As Fig3 shows.

\section{Souvenirs characterized by scenic design}

The excellent tourism city with more than 1680 years old founding history with beautiful scenery 、 good weather and lots of human landscape,the scenic spot area accounts is $22.23 \%$ of the total area land resources,asthesayinggoes, WenZhou is "70 percent mountain、 20 percent water and 10 percent field”, mountain, have already become a part of the soul in wenzhou, like a fairyland of atlas of off 5 a-class tourist scenic spot yandangshan, when is the best representative in mountains,the birthplace of China's kunqu opera is naxi river which called "world monohydrate",solitary island in the middle of OuJiang river north of the city;jiangxin twin towers is a famous cultural relic lighthouses and the world's ancient beacon;“sea island paradise,head hole DongTou”, DongTou as the east China sea pearl in the sea, with clear waters and green hills,changing sea clouds, with seven scenic spots like Fairy pile of rocks、BanPingmountain、The big Quisland、The big Gate island、 The west lake at sea、Bamboolantau island and East sand;apart from these WenZhou also has other scenic spots like Fairy rock、Yaocreek、ZeYa、BaizhangJi and so on it can be said that a great achievement set hill、 river 、 sea 、 island 、 lake and spring together,the natural landscape and human landscape enhanceeachother'sbeauty.Wenzhou has two world geological parks,five national four-level scenic spots, six national key scenic spots, eight provincial scenic spots, one national red tourism classic scenic spot, five national forest parks, nine provincial forest parks, two national nature reserve, 
fifteen national key cultural protection units, etc. Next we designed touristsouvenir based on two scenic spots.

2.1 Yandang mountain near the WenZhou is the holy land that passengers should to go,Yandang mountain, known as "greatest place of interest " famous mountain in sea" reputation,demonstrate、 clever rock and Big Long Qiu three scenic spots called "YanDang top three". Now we took the representative spots as model with the The adornment of the paper-cut in WenZhou, and designed three pendants easy to take and convenient for broadcasting WenZhoujourney,and bring tourists a good story and good memory like Fig 4 shows.
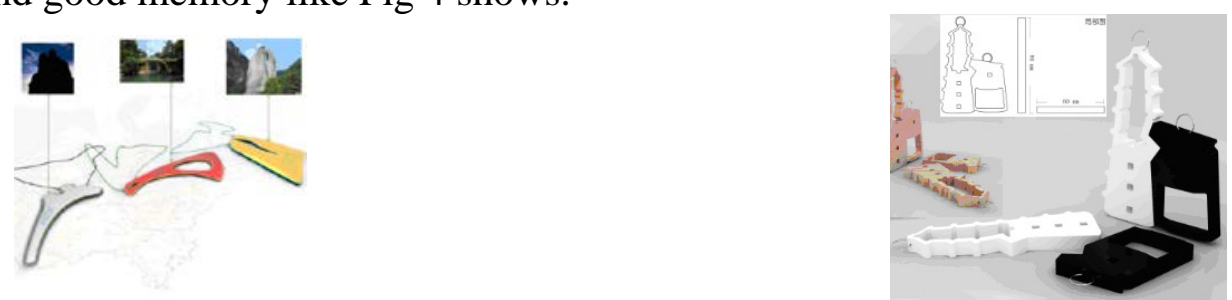

Fig4 Tourism product design with WenZhouYanDang mountain theme Fig5 Tourism souvenir product design with WenZhouJiangXin island theme

2.2 Two towels in JiangXin island, JiangXin island is a oasis set in the OuJiang center, and two towels is the soul of the island, in order to express towel's image with it'sappeal, the same cutting, hollow out with special visual effect, contracted but not simple....., simple processing,commonmaterial, it will be a good and cheap souvenir travel to JiangXin island as Fig5 shows.

\section{Tourism souvenir design with city flower theme}

Some tourism souvenir designs with the elements like WenZhou's city flower Camellia、 city tree banian、 city mark "Wu Ma street、World trade center” like Fig 6 shows.
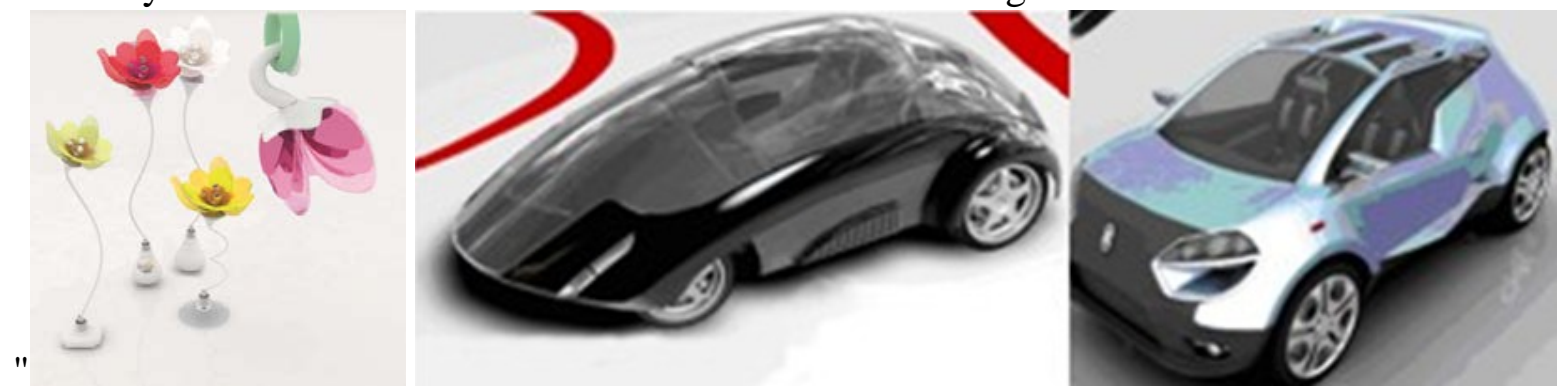

Fig6 Product design with WenZhou city flower and tree theme Fig7 Tourism product design with automobile production industry theme

\section{Tourism souvenir design with WenZhou pillar industry theme}

WenZhou is a shoes capital、penscapital、 lockcapital、pump valve capital、printingcapital、 clothescapital、shave knife production base and automobile production base etc like Fig7、 8 show.
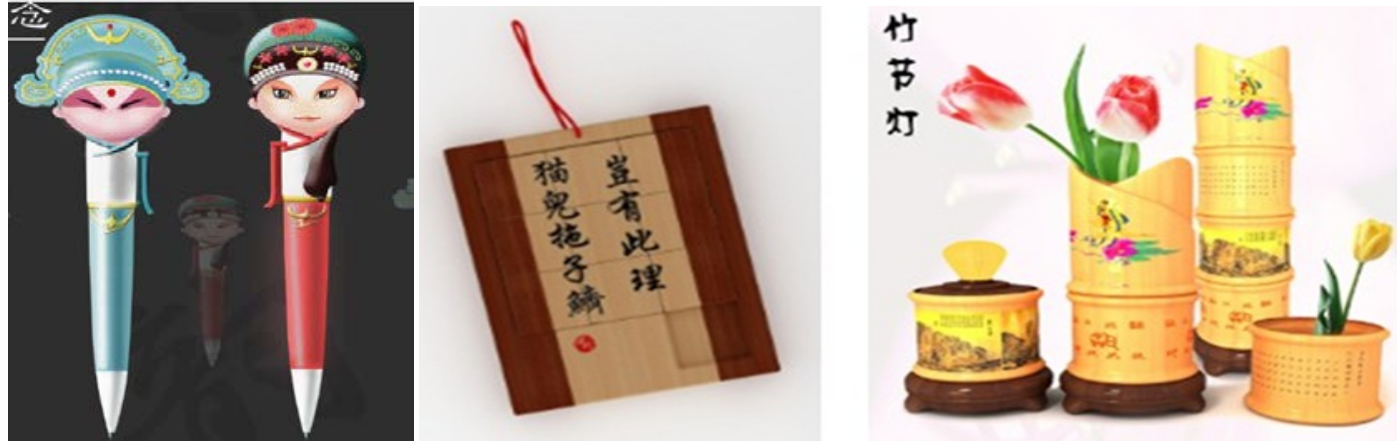

Fig8 Tourism products with pens theme Fig9 Bamboo tourism souvenir designer1 Bamboo tourism souvenir designer2 


\section{Tourism souvenir with agricultural products theme}

There are many kinds of agricultural and sideline products such as Ou orange、 waxberry and some marine products, WenZhou also rich in bamboo, environmental tourism souvenir design represented by the bamboo as Fig 9、10、11、12 shows.

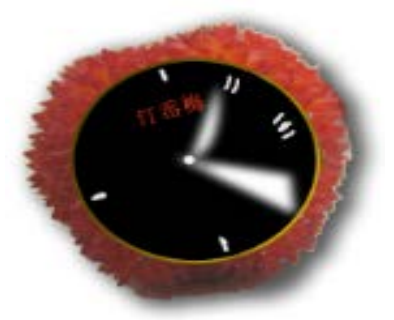

Fig10 Tourism product design with WenZhou waxberry theme
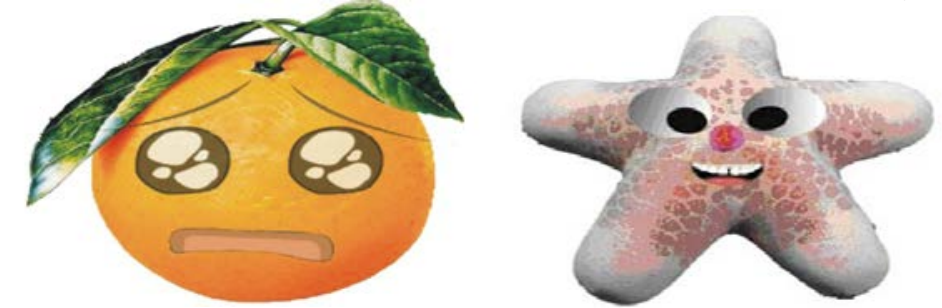

Fig11 Tourism tools with WenZhou OU orange theme Fig12 Beach souvenir with WenZhou seaside

\section{Conclusion}

theme

Better tourism souvenir should be accomplished with design 、 product 、 consumer's full participation,products with good idea can let passengers have an unforgettable journey,the main design thought presented in tourism souvenir, haven been given deeper connotation and higher appearance creativity、 humanitydemand,humanized design is the times and market's demand. In a word, tourism souvenir's humanized design should put in time and energy in human-machine surface 、 aesthetics 、material and ergonomics and science and art,at the same time hold the relevant principle in design,eventually realize the tourism souvenir's innovation with humanization design theory.

\section{References}

[1] ZhiLiang-xia.Packaging design[M].China light industry press,2010,31(14);22-24

[2] Disscussion on fashion and aesthetic of design products-With example of tourist souvenirs design [J]. 《Movie review》,2008(4)

[3] Xuping.Inheritance of Tai Ji element in modern product design[J].Packing Engineering

[4] ZhiLiang-xia,ZHENhe-ye,LIxin.Humanized design of coal mine machinery products[J].Packing Engineering,2008,(4) 29:102-103.

[5] Xiaoyan-sun Culture and the design of tourist souvenirs [J], popularliterature, 2009 (6)

\section{Fund program}

Comprehensive practice program based on professional courses in Wenzhou Vocational Technical institute in 2014 (WZYJG14024) 